established principles of substitution, by the thoughtful application of which to the especial requirements of each individual case, we may claim to have made some headway in the management of disordered infant nutrition. In the selection of the food we must consider all the requirements of the infant at each stage of its development, and a few cardinal principles kept well in mind may serve as a foundation for specialization. Professor Cheadle, in his post-graduate course of lectures at St. Mary's Hospital, London, emphasizes six essential conditions to be observed in the diet of infants:

1. "The food must contain the different elements in the proportion which obtain in human milk," viz., according to Harrington: Proteid, 1 to 2 per cent.; fat, 3 to 4 per cent.; sugar, 6 to 7 per cent.; ash 1 to 2 per cent.; water, 87 to 88 per cent.; or, according to Luff, proteid, 2.35 per cent.; fat, 2.41 per cent.; carbohydrate, 6.39 per cent.; salts, .34 per cent.; water, 88.51 per cent.

2. "The total quantity in twenty-four hours must be such as to represent the nutritive value of from one to three pints of human milk, according to age," viz. proteids, 225 to 675 grains; fat, 231 to 693 grains; sugar, 613 to 1,839 grains.

3. "It must be in a form suited to the physiologic condition of the digestive function of the infant."

4. "It must not be purely vegetable, but must contain a large proportion of animal matter."

5. "It must possess the antiscorbutic element," raw.

6. "It must be fresh and free from all taint of decomposition."

These six statements as to essential conditions seem to be almost axiomatic and if faithfully observed will keep the practitioner quite close to the line of safety.

Since the sources from which the essential ingredients of infant food may be obtained are so numerous, and the facilities of different physicians so varied, it is not strange that a variety of methods of assembling the necessary constituents for a perfect substitute food should be advocated. Eminent observers and experimentors along this line have seemed to array themselves by their practices into three general classes, viz.:

1. Those, who by their use of cereals, treat the human infant as if belonging to the herbivora.

2. Those who would place him with the cainivora and find nothing to meet his physiologic requirements outside of milk, meat juice, animal extracts, etc.

3. Those who by a judicious selection of the essential elements of food from both animal and vegetable sources consider the babe omnivorous. Certainly, analogy, and I believe, also experience shows that the young infant finds its most assimilable and nutritious elements in animal foods, and no teacher of infant feeding has recently laid the world under greater tribute for his positive stand in this direction than Dr. Rotch, the father of the milk laboratory in this country. Believing that the babe should have exclusively animal diet, and that cow's milk contains all the essentials of mother's milk, but in different proportions, he founded the laboratory for the modification by separating cow's milk into its grosser constituents and reassembling them in exact and definite proportions to meet the requirements of the individual case. I have never heard it claimed that there was anything new in the modification of milk. In fact, many practitioners claim to have done this long before Rotch, and wonder why the process should be deemed worthy of a patent. The putting of the idea into practical form through the laboratory, securing uniformity of manipulation by trained experts, the supervision of the milk supply (perhaps the most important feature) and last but not least, the stimulation of keeping exact records, all mark the advent of the laboratory as the longest stride in the advancement of substitute feeding.

The province of the milk laboratory, however, is broader than many would at first suppose from its name. With all due respect to Dr. Rotch I should prefer to call it a "food laboratory," where prescriptions may be compounded to meet the requirements of prescribers who do not believe that all the ingrediients should be derived from cow's milk. Some infants can not digest cow's casein in any form, be the quantity reduced to the minimum limits of laboratory modification, or if only so small an amount can be endured as must of necessity appear in the cream, his nutrition will show faults from lack of proteids. In such cases many of our best men order raw meat juice.

The need of albuminoids when cow casein can not be tolerated (and this condition, I believe, is one of great frequency) must be met by substitution of some soluble, readily absorbed. concentrated albuminoid. No source of albumin in a condition to meet all the requirements of infant digestion, is, in my experience, to be compared with the hen's egg, the white. For many years I have employed it in suitable cases with the most satisfactory results. From the opening of the first laboratory in Chicago, October 1895, I have ordered egg albumin to maintain the necessary percentage of proteids in cases where cow casein was not tolerated. To illustrate by a prescription with ingredients proportioned as follow: Fat, 4.50 per cent.; sugar, 6.50 per cent.; proteids 2 per cent.; which not being well borne, the casein appearing in the stools as curds, is reduced in its percentage of proteids experimentally until the low figure of $\frac{1}{2}$ or $\frac{1}{4}$ of 1 per cent., represents the highest toleration of this constituent of milk.

Since complete nutrition can not long be maintained on such low proteids we must enrich our prescription with albuminoids from some source other than cow's milk. The egg albumin has proved very efficient in my hands for this purpose. To illustrate by prescription: Fat, 4.50 per cent.; milk sugar, 6.50 per cent.; proteids from milk, .50 per cent.; albumin, whites of two eggs; water, q.s. ad 100 per cent.; number of feedings, 6 ; amount of each feed, $6 \mathrm{oz}$; alkalinity (lime water), 6 per cent. Pasteurization is not necessary if due care be exercised in the selection of the ingredients for this emulsion.

\section{SOME PRACTICAL POINTS ON INFANT FEEDING AND INFANT FECES.}

Presented to the Section on Diseases of Children, at the Forty-eighth Annual Meeting of the American Medical Association held at Philadelphia, Pa.. June 1-4, 1897. BY LOUIS FISCHER, M.D.

Professor of Diseases of Children, New York School of Clinical Medicine; Attending Physician to the Children's Department of the German Poliklinik, to the Children's Department of the West Side German Dispensary, to the Messian Home for Children; Consulting Physician to the Children's Department of the United Hebrew Charities of New York, etc. N\&W YORK, $\mathrm{N}$. Y.

To properly determine the value of an infant's food 
be it breast fed or hand fed, we must note the following factors:

1. Does the child appear satisfied and go to sleep after its feeding. 2. How are the stools? $a$, their color; $b$, frequency; $c$, consistency. 3 . Is there any flatulence or colic? 4. Does the child increase in weight, to be determined by the scales once a week, and is the food properly assimilated?

A growing child needs far more food than its weight alone would indicate, for its income must exceed its expenditure so that it may grow. An infant for the first seven months or first one-half year of life should have nothing but milk. Up to this age vegetable food is unsuited to it; it is purely a carnivorous animal.

Human milk contains about 4 per cent. of proteids (casein), 2.6 per cent. fat, 4.3 per cent. carbohydrates (milk sugar). Of the solids, the proteids make up 36 per cent., the fats 24 per cent., and the carbohydrates 39 per cent.

In a typical adult diet, the proteids amount to 20 per cent. of the solids, fats 15 per cent., carbohydrates to more than 60 per cent. The diet of the infant is, therefore, nearly twice as rich in proteids, half as rich again in fats, and a little more than half as rich in carbohydrates as that of the adult. It is, therefore, in a physiologic sense a luxurious diet.

The strain of growth falls heavier upon the more precious proteids than upon the more cheap and common carbohydrates. ${ }^{1}$

Rotch, speaking of proteids (p. 174) says the proteids as a whole are a valuable source of information as to whether the milk is normal or abnormal. The following formulæe indicate the proper percentage required for hand-feeding at birth of the infant-and at several other periods thereafter with the same formulæ translated for home preparation, where the luxury of a laboratory can not be afforded. Proper sterilization of bottle.nipples and food is self-understood and it is not the purpose of this paper to elaborate on the same.

Child at birth. Formula 1.-New-born infant's food. Fat, 1.0 ; sugar, 5.0 ; proteids, 0.75 ; reaction alkaline. Ten feedings ( 30 c.c. each) heated thirty minutes to $167 \mathrm{~F}$. The formula for home use is the following: Cream, 2 ounces; milk, 2 ounces; lime water, 1 ounce; water, 15 ounces ; milk sugar, $6^{3} 4$ drams ; cream must contain at least 10 per cent. of fat.

Child one month. Formula 2.-Fat, 2.0; sugar, 5.0; proteids, 0.75 ; lime water, 5.0. Formula for home use: Cream, 4 ounces; milk, none ; lime water, 1 ounce ; water, 15 ounces ; milk sugar, 63 , ounces.

At four months. Formula 3.-Fat, 3.5; sugar, 6.5; proteids, 1.5; lime water, 5.0. Formula for home use: Cream, 7 ounces; milk, 1 ounce; lime water, 1 ounce; water, 11 ounces; milk sugar, $6 \frac{1}{4}$ ounces.

From nine to twelve months. Formula 4.-Fat, 4.0; sugar, 7.0; proteids, 3.0; lime water, 5.0. Formula for home use: Cream, 8 ounces; milk, 71/2 ounces; lime water, 1 ounce; water, $31 / 2$ ounces ; milk sugar, $63 / 4$ ounces.

Stool of a nursling.- The stool of a nursling or a baby on an exclusive milk diet should be yellowish in color, smeary or pasty-like in consistency and have an acid reaction. The smell should be faintly acid but not disagreeable. The color is due to bilirubin and the reaction depends on the presence of lactic acid, the source of which is the milk-sugar. The only gases present are $\mathrm{H}$ and $\mathrm{CO}_{2}$. According to Escherich, $\mathrm{H}_{2} \mathrm{~S}$ and $\mathrm{CH}_{4}$, to which the odor of adult stools is due, are not present. There are no peculiar albuminoids. Those existing in mother's milk seem to be entirely absorbed. Peptone exists in trifling amount. Sugar

" "Stewart's Physlology," p. 412, 1897. is not present. Pancreatic ferment is absent and sometimes traces of pepsin have been found. Mucus is always present in considerable quantity, also columnar intestinal epithelium.

In the stools of nurslings, large quantities of lactate of lime can be found, so also we frequently find oxalate of lime depending on the quantity of oxalate of lime ingested. Uffelmann has noted the presence of bilirubin crystals in the stools of nurslings, in perfectly healthy children.

Miller, who carefully studied the various microorganisms in the mouth, found that most of them could again be found in the intestinal canal. He further found that certain germs possessed diastatic properties and were capable of producing lactic acid fermentation. In the milk feces of nurslings Escherich found two germs, the one he called bacterium lactis aerogenes (or bacterium aceticum, Baginsky) and the other the bacterium coli commune. In the meconium he found proteus vulgaris, streptococcus coli gracilis and bacillus subtilis. The number of stools during the first two weeks is from three to six daily. After the first month the average is two stools daily; many infants have one, others three stools daily. This latter is due largely to the excessive quantities of water given to infants.

As soon as the exclusive milk diet is changed to the mixed diet we then loose the characteristic infantile stool and they resemble more those of an adult, though remaining softer and thinner throughout infancy. They become darker in color, assume the adult odor and have more varieties of bacteria than those previously mentioned as found in the stool of a milk diet. Reaction of stools.-R Raction of stools in diarrheal disease and in health is chiefly acid or, next in frequency, neutral. Alkaline stools are rare. Greengrass stools, usually acid, are seen in the early stage of dyspeptic diarrhea, the color from a pale greenish yellow to grass-green, owing to improper food.

Wegscheider has shown that the green color is the result of preformed biliverdin. The condition in the intestine, upon which the transformation of bilirubin into biliverdin depends has been generally regarded as one of acid fermentation.

Experiments.-Pfeiffer's experiments ("Verdauung im Säuglings-alter bei Krankhaften Zuständen" Jahrbuch für Kinderheil., Bd. xxviii, p. 164) show this former opinion to be wrong. He found that none of the acids formed in such fermentation, lactic, acetic, butyric, propionic, etc., added to yellow stools outside the body, turned them green, but that they made them deeper yellow. Butdilute alkaline solutions added to fresh yellow stools turned them green after an exposure of thirty to sixty minutes and strong solutions turned them, first brown, later, after exposure to air, intense green.

Typical green stools.-Typical green stools can be produced by giving an infant two or three grains of bicarbonate of soda. This I have tried dozens of times; the soda must be given for a few days. This explains Pfeiffer's alkaline theory. Typical green stools can also be produced by giving small or even large doses of calomel. If, after having given bicarbonate of soda and produced green stools, we give diluted hydrochloric acid in 5 to 10 drop doses, the yellow color will in a few days again reappear. This is also true in giving rhubarb.

Stools.-Stools which are pale yellow when discharged, and which afterward become green, are often 
seen in disease. They may be themselves neutral or alkaline in reaction; this latter may however depend on the admixture of urine. An excess of bile may often cause very green stools.

Broucn stools.-Brown stools may be due to changed biliary pigment and to drugs, i.e., bismuth causes the well-known dark stool; so also tannic acid and all iron salts give the dark stool which varies from a deep brown to a black color.

Blood in stools.-Blood from the stomach or small intestine frequently gives the stool a black color resembling tar. Thus a practical point in Boas' "Diagnostik der Magen- und Darmkrankheiten" is, that the brighter the color of the blood the lower down near the rectum and anus must the pathologic lesion be looked for; the darker the blood the higher up must the cause be found, e.g., the diseased conditions exist in the stomach, duodenum, jejunum, etc., if the stool contain black blood. If the corpuscular elements of the blood are wanting, then the presence of blood can only be positively diagnosticated by either a microchemic examination or by means of the spectroscope. The presence of red blood corpuscles must always be regarded as a pathologic factor.

Brown stools, muddystools.-A brown stool in an infant is frequently caused by a diet of animal food or by a diet principally of broth. These stools have no distinct consistency nor reaction. In dyspeptic diarrhea or in some forms of enterocolitis we have very offensive stools and they resemble muddy water; with the latter there is considerable flatus during each movement.

White or light gray stools.-White or light gray stools usually are of a putty-like consistency, sometimes like dry balls on a diaper; sometimes they appear like ashes. Uusually they are very offensive, consisting principally of fat. In the latter there is scarcely a trace of bile, or the latter may be absent altogether.

Mucus.-Mucus is always present in all healthy stools and is so well mixed with the stool that it does not appear as mucus to the naked eye. Any appearance therefore of mucus easily visible should be regarded as abnormal. Mucus is present in every form of intestinal disease. Very abundant in inflammatory conditions affecting the large intestine, more so than in those affections of the small intestine, and especially so in inflammatory conditions of the colon, both acute and chronic.

Jelly-like masses.-Jelly-like masses of shreds of mucus, and where the stool consists chiefly of mucus, show that the affection is confined to the lower portion of the colon or that it is located in the rectum.

Long shreds of mucus.-Long shreds of mucus, frequently resembling false membrane, are often found in catarrh of the large intestine. If the shreds of mucus are intimately mixed with the stool, then we must look for the lesion quite high up, and if it comes from the small intestine it is usually stained from bile. If the lesion is low down the mucus is not intimately mingled with the stool.

Dyspeptic stool.-The first change noticed in the dyspeptic stool is the increase of fat. Often the stool is quite green and contains small pieces, of yellowishwhite color, which vary in size from that of a pin-head to the size of an ordinary pea. Hitherto, from their color, they were supposed to be casein lumps. Wegscheider has taught us that they consist principally of fat. Baginsky has shown that large colonies of bac. teria are contained in these lumps of fat. Frequently they are so numerous that it looks as though the stool were composed only of these cheesy lumps. They can be easily differentiated from real casein lumps by their solubility in alcohol and ether.

Fat diarrhea.--Biedert and Demme have devoted considerable attention to this subject. (See Biedert "Fett-Diarrhea" in "Jahrbuch für Kinderheilkunde," 1878). In some children the feces showed 50 to 60 per cent. of fat, whereas the normal percentage in ordinary feces varied from 13.9 per cent. (which is the normal quantity) according to Uffelmann.

Case in is not nearly as common an ingredient of feces as is commonly supposed, as J have previously stated. Casein lumps can be seen in abundance in the course of a diarrhea during an exclusive diet of milk.

Quantity of feces.-The quantity of feces varies, but it has been found that 100 grams of milk food will produce about 3 grams of feces, according to Baginsky. This is a vital point, but I have found it very difficult to determine, for in most cases the napkins of the infants are soiled with urine plus the feces, thus adding to the gross weight.

Proteids.--The proteids of milk are so thoroughly absorbed that only small traces of them can be found in the feces. Normal milk feces contain large quan. tities of bacteria, but chiefly two kinds, previously mentioned, viz., bacterium lactis aerogenes (Escher. ich) and bacterium coli commune. Other germs, especially those of the protolytic type ( $i$. e., those that render gelatin fluid) are not found under normal conditions .

Albuminous decomposition and its products, tyrosin, indol, phenol and skatol, are not found in milk feces. But lactic acid, acetic acid, formic acid und other fatty acids are present, causing the acid reaction. Sacchurine ferment. $-V$. Jaksch found a saccharine ferment in the feces of children.

Peptonizing ferment.-Baginsky found a peptonizing ferment also in infantile feces.

Escherich in "Jahrbuch für Kinderheilkunde," "Beiträge zur Antiseptichen Behandlungs-methode der Magen-Darmkrankheiten des Säuglingsalters" says: If albuminous decomposition with very foul offensive stools exists, these articles should be withheld from the diet and carbohydrates given, dextrin foods, sugars and milk. If acid fermentation is present, with sour but not offensive stools, carbohydrates are to be withheld and albuminous foods given, such as animal broths, bouillon, peptones, etc. In the decomposition of milk, the sugar of milk and not the casein is usually broken up.

Holt ("Artificial Feeding," p. 179) says: Regarding the exact indications according to which fat, sugar and proteids of milk are to be varied, much remains to be learned.

Sugar is too low.--If the sugar is too low the gain in weight is apt to be slower than when furnished in proper amount.

Sugar in excess.--Symptoms indicating an excess of sugar: Colic or thin green very acid stools, sometimes causing irritation of the buttocks; sometimes there is regurgitation of food and eructations of gas. Excess of fat.-Excess of fat is indicated by the frequent regurgitation of food in small quantities, usually one or two hours after feeding. Sometimes an excess of fat causes very frequent passages very nearly normal in appearance. In some cases the stools contain small round lumps somewhat resembling 
casein, but really masses of fat. This has already been mentioned in speaking of the differentiation of true casein curds and small fat lumps by the solubility of the latter in alcohol or ether.

Diy pasty stools. - When too little fat is given, it is indicated by hard dry pasty stools, and usually constipation. This can be easily remedied by the addition of cream three-fifths of which is fat. Holt speaks against increasing the fat above 4.5 per cent. in infants under six months old, and believes we should not go above 4 per cent. The following case is presented to illustrate the difficulties encountered in the ordinary feeding of a healthy child.

N. R., a healthy female, was put, soon after birth, on modified milk.

October 14.-Fat, 2.0 ; milk sugar, 5.0 ; albuminoids, 0.75 ; lime water, 1-16. Eight feedings; 2 ounces in each.

October 17. Constipation. - Fat, 2.5 ; milk sugar, 6.0 ; albumin, 1.0; lime water, 1.16 . Nine feedings ; $2 \frac{1}{2}$ ounces in each. October 27. Fat, 3.0 ; milk sugar, 6.0 ; albuminoids, 1.0 ; lime water, 1.16; barley jelly, 1-15. Ten feedings; 3 ounces in each.

November 5.-Fat, 3.5; milk sugar, 6.0 ; albuminoids, 1.0 ; lime water, 1-16; barley jelly, 1-15. Ten feedings; 3 ounces in each.

November 17.--Fat, 4.0 ; milk sugar, 6.0 ; albuminoids, 1.5 lime water, 1.20; no barley. Ten feedings; 3 ounces in each.

November 19. Curded stools, dyspeptic diarrhea.-Fat, 4.0; milk sugar, 6.5 ; albuminoids, 1.0 ; lime water, $1-20$. Ten feedings; 3 ounces in each.

The child did not increase in weight, had a rectal temperature of 100 degrees, slightly furred tongue, vomited curds, had greenish stools containing undigested particles of fat and true casein, and large masses of mucus. The diagnosis of dyspepsia infantum was made. Hand feeding was stopped. The child's alimentary tract was cleaned by giving cascara sagrada, and a proper wet nurse was secured. The infant was now about 6 weeks old. The child nursed well and improved in weight and the character of stools was changed. The child improved until it was 7 months old, when it did not increase in weight. As the child was bright and otherwise cheerful, it was decided to have the milk of the wet nurse examined by a competent chemist. Through the courtesy of John S. Adriance, the chemist of the Nursery and Child's Hospital, I found the following: Fat, 2.000 per cent.; sugar, 7.431 per cent.; proteids, .882 per cent.; ash, .162 per cent.; total solids, 10.475 per cent.; water, 89.525 per cent.; specific gravity at 70 degrees F., 1.0316; reaction alkaline.

In the result above given it is very evident that a deficiency in proteids exists, hence it accounted for the late dentition and also for the stationary weight. The child did not gain an ounce in one month. We discharged the wet nurse.

I ordered: Milk, 3 ounces; cream, 2 teaspoonfuls; oatmeal jelly, 3 ounces; lime water, 1 dram; milksugar, 1 teaspoonful; one pinch of salt; sterilize and feed every three hours.

The child has taken this food for six days and I was pleased to learn at the time of writing that the child is cheerful, takes the bottle very well, has had one and two yellow stools daily, and has gained six ounces in six days. Thus we must adapt our food to suit each individual body; for, this infant did so poorly on modified milk and did very well on a wet nurse for a given time. It shows that the chemic examination should be made at least once a month, and at once if we find the baby not increasing in weight, or the character of the stuols abnormal.

Proteids in excess.-Proteids in excess are indi- cated by the presence of curds in the stools. This is the most frequent cause of colic in infants. Sometimes there is diarrhea, more often constipation when the proteids are in excess. This excess of proteids frequently causes vomiting and so does an excess of both fat or sugar. If, therefore, after reducing the percentage of proteids, fat and sugar, vomiting still persists, then we must feed the baby with smaller quantities. Thus we may have to give a four ounce bottle where a six ounce or a five ounce feeding causes vomiting. Certain rules can be laid down; if an infant does not thrive, $i$. e. does not gain in weight without showing any signs of indigestion, then the proportions, i.e., percentages of all ingredients, should be gradually increased, chiefly the proteids, however, for the latter is the most important element in an infant's food.

Adriance after an examination of breast milk, both clinically and chemically, arrived at the following conclusions:

1. The fat shows no constant changes during lactation. Its most marked characteristic is its variability. 2. The carbohydrate on the second day of lactation is low, but it rises rapidly during the first fow days; this increase continues, but less rapidly up to the end of lactation.

3 . The proteids pursue a course the reverse of the carbohydrates.

4. The salts diminish similarly to the proteids.

5 . The total solids are represented by 12.20 per cent. till the later months of lactation when they decrease steadily.

6. The colostrum period has low carbohydrates with a tendency to decrease rapidly.

7. The milk of the later months of lactation shows a deficiency in proteids and total solids.

The moment, then, that we find the baby not increasing in weight, or apparently hungry, the milk should be carefully examined for its proteids, and if the milk is deficient in this latter element then weaning must be insisted upon, for the proteids are the prime factors in infancy needed for growth, and deficiency therein will result in rickets and lay a foundation for all those conditions commonly called tuberculous.

The amylolytic function usually develops after the eighth or ninth month, at times toward the end of the first year; then starchy foods are called for, for the child's function can now transform this starch into sugar. The cereals should be given and Jacobi's plan, oatmeal where constipation or a tendency thereto exists, and barley or rice where a tendency toward diarrhea or loose bowels exists, is the most successful. To permit the indiscriminate use of cereals or to allow all patent foods to be given according as they are labeled is wrong, and many a case of rickets could have been avoided by a careful study of the infant's diet. Condensed cream.-Hundreds of children in apparent good health appear at the children's department of the various institutions with which I am connected. I have examined them and find some in excellent health with no sign of rickets, then again hundreds appear with the same form of food and show the worst kind of rickets. Thus, while some thrive on a given food others do not. So condensed cream will be lauded by the mother whose baby is well, and again the same food will be condemned by the mother of an infant whose rickety head, bones and muscles are founded on an impoverished diet of condensed 
milk. We can account for the rickety child, but we can not account for the healthy one on the same food. Modified milk-While modified milk as it exists in the Walker-Gordon Laboratory has its advantages, much remains to be accomplished. For people who can not be relied on to properly sterilize or Pasteurize their milk, the laboratory will be beneficial. I have given the milk a careful trial in some of my best families and can not give it an indiscriminate recommendation. Constipation of the worst form was encountered in the child of a physician for whom I prescribed Walker-Gordon milk, and this proved so obstinate, although I modified the prescription by increasing the fat and lowering the proteids, that we finally abandoned it. This baby, fed on oatmeal and milk combined with a sterile albumin water, made a complete recovery without medication. Another child, also the child of a physician, for whom I prescribed modified milk, encountered this obstinate constipation and I finally abandoned this form of feeding and tried Mellin's Food, which agreed quite well with it. It is evident that in giving any form of feeding we must study the result. As each child is different in appearance so also are the requirements totally different. We must not overlook individual idiosyncrasies, for what will agree with one baby must not necessarily agree with another.

The microscopic examination of human milk.Rotch says (page 169): Microscopic examination of milk is of value for the determination of the presence of pus, blood, epithelial cells, colostrum corpuscles and foreign matter. But the chemic analysis is the only one which can be depended on, for although the microscope may show yellow coloring matter and apparently be rich in fat, it may be misleading and not always prove so by a chemic examination. Thus, human milk of a green color (evidently produced by micro-organisms) may not even show under the microscope.

Specimen of breast milk for the chemist.-..To obtain a specimen of breast milk for analysis, wash the hands so that they are sterile, and the breast and nipple with sterilized water, from 20 to 30 c.c. ( 5 to 8 drams) of milk drawn by the breast-pump, which being made of glass can be thoroughly washed, is poured into a sterilized bottle and tightly corked. The milk should be put on ice until the chemist is ready for the examination.

Both quality and quantity requisite.-- Chemic analysis is not all; although the analysis may show the milk to be of an excellent quality an infant may not thrive owing to an insufficient quantity. The symptoms showing a deficient supply of milk being that the breasts at the time of nursing are soft and that only a small quantity can be extracted from them at the nursing time. A period of nursing longer than usual (which is fifteen or rarely twenty minutes) should lead us to suspect the milk to be lacking in quantity. We can also determine the actual quantity a child has swallowed by weighing it immediately before and after the nursing.

If we have habitual colic reduce the percentage of proteids; if frequent vomiting soon after feeding, reduce the quantity of each feeding. For regurgitation of sour masses of food, reduce the fat and sometimes also the proteids. For obstinate constipation increase the fat, also the proteids.

Rachitis.-Rickets is caused by an improper quantity and quality of food. It is evidenced by constipation or by hard pasty stools in early infancy. Unless the food elements are altered to modify this condition it is manifested by late dentition or by the appearance of carious teeth; the bony structures are not firm; the muscles are flabby; in some instances the children are fat. Examinations of a large number of children have shown that it is not the fatty elements but the lack of proteids upon which this rachitic condition is based. When children placed on starchy foods show constipation it is to be considered a danger signal that the food is improper. It is only too plainly evident that we must individualize and can not lay down general rules and each case should be considered eeparately.

187 Second Avenue.

DISCUSSION ON PAPERS OF DRS. COTTON AND FISCHER.

Dr. J. P. Crozer-Griffith of Philadelphia-One of the things $I$ have maintained strongly is the necessity of foeding the child at the mother's breast when it is at all possible to do so. At first thought this might seem altogether unnecessary, but still we know of physicians who make it a practice to wean the child very quickly when there is no necessity for it, maintaining it can be fed just as well on the bottle. It is true the child may be fed well on the bottle, but nobody can tell whether a child will do well on a bottle. Leaving the mother out of the question, there is no good reason for weaning the child unless it has to be weaned, and so I think it is well for us to consider whether or not we can not modify the mother's milk before we consider weaning the child. Next is the idea of having the prepared milk of the same percentage as in the mother's milk. The two substances are not alike. Although they may have the percentage the same, of different proteids, still we have different substances in the cow's milk and human milk. So it does not follow that 1 per cent. of albuminoids in the cow's milk will be digested as well as 1 per cent. of albuminoids in the mother's milk. We must try to determine what percentage of the different constituents the child will take and that of ten can be told only by trial. So to be on the safe side we should begin with percentages distinctly lower than we will expect the child to take. We as physicians must not forget that we are dealing with a living organism and not a machine, and we must not force our children too much to be fed. That is one danger of our modification of milk which we must uphold. Therefore we must be ready to make any changes necessary to sustain the individual case.

Dr. W.S. CHRISTOPHER of Chicago-The subject is altogether too large to discuss more than one phase of it in detail. I would especially direct attention to a point brought out, that is that condensed milk has a use. I have found there are conditions under which condensed milk is absolutely essential if life is to be saved. The dangers of condensed milk we will all admit. That it is a milk deficient in fat and proteids and that it leads to the production of scurvy and rickets we all know. but it need not lead to those things in the hands of those who know how to prevent them. Backing up the use of it with codliver oil and beef juice and some fruit juice for the antiscorbutic use, we have a food that is almost perfect. We find children who require condensed milk to avoid the poisonous effects from cow's milk, poisonous not in the sense that the milk is infected, but even pure milk will produce in the system of some children a substance apparently toxic which they can not bear. So I have had to take children from the breast and put them on condensed milk, when their trouble would immediately cease. The indications for the use of condensed milk appear to be these: I use it in children who have a predis position to vomiting, so called "spitting babies." It is given not for the purpose of keeping the food down, but these children seem to have less of their disturbance when fed on condensed milk. It has been my experience to take children from modified milk, for instance, in which the albuminoids had been cut down almost to starvation and the fats greatly reduced to stop vomiting, and the form of albuminoid that could be borne was found in condensed milk. When condensed milk is not borne I have sometimes found that dried milk is. First I would give a sterilized milk and second $a$ milk that has been boiled and the coagulum removed. 
Chalrman-Doctor will you tell us what you mean by steril ized milk?

Dr. Christopher-I refer to one in which a temperature as near 212 degrees as possible is used. When we boil it we can remove the coagulum, and $I$ think in the coagulum there is removed from the milk a substance which tends to produce these irregular features in children. If this is not sufficient, condensed milk will be frequently found satisfactory. If not then resort to dried food, Nestle's food or what not, and in this shape the albuminoids are rendered indigestible and can not be absorbed by the child and consequently escape it. In not only the "spitting child," but also in the child that has a tendency to the formation of gas on the stomach, eruptions on the skin or catarrhal affections, this type of food will do better than raw milk.

Dr. T. M. Rotch of Boston-The more advances made in infant feeding the less I feel I know about it. The greatest advancement in infant feeding, I think, is that we are getting rid of the old effete ideas about it, the fears that came up about the use of cow's milk, and we have in their place an instrument that we can use, an instrument which is exact, an instrument which in the future will save the lives of a great many children. I I think the fault of infant feeding lies in the physicians themselves. We do not know how to use, for instance, the different percentages. We are just in the very infancy of our knowledge. The exact modification of milk is in embryo; it is not old. In former days they modified milk by mixing cream and milk, and they do now, but that in no way compares with the exact percentages we will deal with in the future. Now we can get those exact percentages and we are just beginning to use them. After we have used them five or six years we shall be more exact in our knowledge. But to say the children can not digest the lower percentages I think is not exact and is incorrect. I was much interested in Dr. Cotton's remarks. It is important to know the quantity of fat. It seems to me that in the future the busy physician will not make the analyses himself; I think it will be left for experts to say what are the percentages, and the physician will learn to think and speak in percentages. We will know, after experimenting with exact percentages given by exact analyses, which very few of us can make, for the physician in general can not make them, and then we will simply give the percentage we desire, for instance, the three of fat, six of sugar, perhaps, and one of proteids. These will be sent to people we know will put them up exactly, just as we now do our prescriptions of drugs. If you follow the history of the giving of druge it corresponds with the history of prescribing milk. My great grandfather in Pennsylvania, for instance, used a mortar, which I have, to compound his drugs, that we now have put up by the apothecary, and in the future I think we will send to the laboratory our prescriptions for infant food, which are much more difficult to write than are the prescriptions for drugs in disease. But it is important, as the Doctor has said, for us to get them until we have confidence in the laboratory as we have in the apoth. ecary shop.

Then as to mother's milk. There is nothing definite known about the analysis of mother's milk. Good human breast milk differs in percentage. So a child may do well when nursed by its mother but may have indigestion when given to a wetnurse, not that the milk is not good, but because it is not adapted to the use of the special infant. It is in the variety of the milk in which lies its virtue and not in its exact percentage, and so we must vary our foods over and over again for the special child. It is not in any one component part but in the general composition of the food. For instance, in the formula Dr. Cotton has given us the 4.50 is entirely out of proportion with the .50 . I can not tell the exact proportion, but with the proper combination of the different constituents we can make use of the albuminoids which exist in cow's milk.

Dr. Jas. J. Concanon of New York-I have had to look over something like three or four thousand children every year and I have been accustomed to the fact that nearly every kind of artificial food will fail in many cases. The mother's milk is not only different in different women, as Dr. Rotch has said, but it varies in the same woman according to her condition and according to her diet. The various things referred to have all been tried in my practice, the use of fruit juice to prevent scurvy and the use of barley. water when the child will not retain the milk. In many cases when the cow's milk will fail they sup. ply a want and the child thrives. I do not know how it is throughout the country, but in New York we can easily obtain goats, for there we have a large Irish population. The subject of working up artificial infant foods is largely overdone. We ought to try more to compel mothers to nurse their children. I think about ona-fifth of the children artificially fed are fed so because mothers will not nurse them, but give up nursing at the end of the second month for various reasons. Some believe they do not give the child sufficient and the breast dry up. There is one thing you can never put in an artificial food and that is the antitoxic property in the mother's milk. We all know, who have auything to do with diphtheria, that the nursing child at the mother's breast is immune. I always, when immunizing for diphtheria, let the child go without an immunizing dose when it is nursing under nine months. After the tenth month the milk loses this quality. This you can not get in the artificial foods.

Dr. KeLley, of Ohio-I would like to inquire of Dr, Cotton how he determines clinically when to add more fat and when to reduce the fat; when to add albuminoids and when to reduce the albuminoids, and so on with the sugar? How does he determine the quantities and whether they are right or wrong?

Dr. Coleman of Alabama - I believe the day will come when thousands of infants will be saved to humauity by the food advised by the able authorities today. But now I wish to speak more especially to the gentlemen situated in the country dis. tricts and in towns with 10,000 or less inhabitants. These proportions are the things we want. If we can get our modified cow's milk with cream or bicarbonate of soda or a pancreatic extract, that is what we want. But there is another thing that stress has not been laid on here and that is the manner of feeding the infant. More harm arises from the contamination of the milk after the family gets it in their hands before the child gets it into its stomach than we can imagine. If we can impress the importance of exercising extreme care in handling the milk, then we have done much for our patients. I do not think it is right to feed the child with a spoon and cup al together, but when the infant is three months of age we can greatly eliminate the dangers of the nursing-bottle, and especially the use of the long nursing-tubes.

Dr. Edwin Rosenthal of Philadelphia -I would like Dr. Roteh to answer a few questions. How about children who are partly fed by the breast? How should we proceed with them? And another thed of burning the milk and using flour which has been changed by fire? I begin with a child only one day old by giving it half milk and half water. I rarely use sugar in any shape or form: I have not used it in either of my own two children. I use for the taste a little cinnamon. Albumin I use in any kind of dose; this I give raw, as much as an egg every hour or two, in water, to an infant of three or four months, and I mix with this albumin, salt. In regard to the formula by Dr. Cotton, I have always made my proportions in tablespoonful doses. It would be well to know how to prescribe the metric system in that way. I would like to know how much he considers the two eggs to represent. Among a certain class of people they use a preparation they call zweiback. Oatmeal water I have seen given to children, but a good many of them become scorbutic. One case, which I fed on sterilized milk, became rickety.

Dr. T. M. RотсH of Boston-In the present state of our znowledge in regard to the feeding of infants during the first year of life it is not necessary to discuss the various artificial foods which have been given in the past. It is accepted by the medical profession that human breast milk, when of proper quality and adapted to the especial infant, is the best food that can be given to infants, and that when this food can not be given, cow's milk, modified so as to approach as nearly as posIn human breast milk, should be used.

In regard to what Dr. Cotton has said concerning certain infants not being able to digest the proteids of cow's milk, and his advice as to the substitution of egg albumin, I would say that in past years, before the opportunity was given to modify the proteids in cow's milk for the especial case, I also had much difficulty in making certain infants digest the proteids of cow's milk. I have also given egg albumin in the manner in which Dr. Cotton has suggested. At the present time, however, I meet with fewer and fewer cases where the proteids can not be given, and this is due to the fact that through the newer methods for the proper modification of milk in all its constituents we can in the vast majority of cases adapt such milk to the infant's digestion, even when its digestion has been weak ened by improper foods. I do not believe that there is any especial virtue in the albumin of eggs, and I am not aware that a sufficient essential chemic difference has been shown to exist between such albumin and that of cow's milk to warrant our substituting it for the proteids of cow's milk. We know that the coagulable part of the proteids of cow's milk is proportion ately greater to the non coagulable than is the case with human milk, and that, therefore, it is wiser to give a proportionately smaller amount of proteids to an infant who has difficulty in digesting the proteids of cow's milk, in comparison with the 
percentage of proteids which the infant would receive in human milk. I should also draw your attention to the fact that it often is not the proteids which are disturbing the infant's digestion, but the improper combination of the fat, sugar, and proteids, which by adjusting more carefully will of ten agree with the infant, while the same percentage of proteide without proper adjustment would apparently cause disturbance of digestion.

Dr. Cotton has shown us a very valuable addition to the means which can be employed by the physician for preparing a substitute food for the infant in that he has shown us an apparatus by which the percentage of fat in the milk can be determined very easily. This is a step in the right direction, as it is the fat which varies so greatly in milk and wherever we can find the exact percentages of the different elements of milk, and can combine them in such a way that their exact percentages in the combination shall be known, is always valuable. I would sug. gest, however, that history repeats itself, and that the modifi cation of milk by the physician himself, and in the family, will in the future probably fall into disuse, just as the combining of drugs in the physician's office has been mostly done away with. The milk laboratory will take the same place in the community as does the apothecary shop, and in the future the physician will find it both an instrument of precision and a means of sav ing time and labor for himself.

In regard to what Dr. Christopher has said concerning condensed milk being of vital importance for certain infants, I think that the experience of most of us has shown, and future investigations will show, that such a position as he takes is incorrect. In the first place he is not dealing with exact percentages when he gives condensed milk to infants, since the different brands of condensed milk vary very considerably; for instance, the percentage of fat varying from 2 to 28 per cent. There may be other reasons, as he has stated, for using condensed milk, but the very fact that the proper adjustment of the percentages is well known to be so important in the management of difficult digestion will in the future relegate condensed milk for the feeding of infants to the position of a food which has not proved satisfactory to the physician at large.

In regard to what Dr. Cotton asks as to the indications for increasing the fats, proteids, etc., I would say that it is well to begin with a low percentage of both fat, sugar, and proteids, and when the infant is digesting this combination well, to in crease the percentages gradually until the infant shows that it is not only digesting the food but that it is getting a sufficient quantity of the elements for its nutrition by increasing in weight. Through means of the laboratory we are able to give any percentage of any of the three constituents of the milk, the fat, the sugar, or the proteids, which we wish and also to give them in any combination which we wish. Having this instrument of precision to work with we must, by noting our successes and our failures, elaborate a more complete system of treating the various phases of infantile indigestion than any we now possess, for we have none of us used the laboratory long enough to be able to say definitely in each case whether any one of these constituents should be increased or diminished.

Dr. ByERs of Alabama-I should like to ask Dr. Rotch what he regards as the normal standard of mother's milk?

Dr. RoTCH --That is obtained by averages, but you can not deal with averages when you are feeding an infant. You have to take the individual. You may take fifteen infants and change them to the breasts of other women, and you will find they wil not do well.

QUESTION-Do you use the average as the standard and get the constituents from that average?

ANSwER-That is the trouble; we do not know the percent age in the individual case.

Dr. Enwin E. GRaham of Philadelphia-I have discussed this subject with a number of physicians in Philadelphia and they all seem to be verging the conclusion arrived at by Dr. Rotch, that the more they use of milk from the laboratories the more persistently they stick to certain percentages for certain ages and vary those within certain limits, the better are the results they obtain. This conclusion I think has been forced upon them, because the feeding of the child by the laboratory method is certainly neither the most convenient nor the most economic. It involves an amount of study that is out of proportion to what physicians as a rule are in the habit of giving the subject, and it involves an amount of time that could very well be devoted to other subjects. Still the fact that phy. sicians ail over the country are adopting the method, and the sale of this modified milk is rapidly increasing, tends to show that the trend of modern opinion is toward the use of modified milk, modified according to definite methods.

Dr. J. A. Larrabee of Louisville-I have listened with a great deal of interest to the subject of infant feeding, but I will not take up your time unnecessarily with the points already gone over. The whole thing seems to show too much science. I doubt if we shall ever formulate rules that will apply to all cases. What is one's meat is another's poison, is a better rule than any other we know. What agrees admirably with one child will not agree with another; it is a matter of speculation and individuality in each case. If we hit it right we do well, but we will shoot no worse if we aim at a mark. So it is well to have formulated plans. But $I$ think we can never prepare a food of which we can say, "Go and give this to your baby and it will be all right." As to goat's milk, I do not know why that should be a panacea. It is true the goats may feed on newspapers and the infant may acquire an immense amount of literature in that way. The higher the goats climb, perhaps the more casein the infant may get. We all know the climbing nature of the goat; and nobody would be foolish enough to rent a level pasture for his cows if he wants to make cheese. I should say that goat's milk, instead of being a panacea at all for infants, will be better suited to those who raise goats; because it is said a penitentiary diet is good for penitentiary people. As to the immunizing property, I think the Doctor has the wrong idea. The immunity in these cases comes from the infant not getting the germs. If the baby is nursed at the breast and the breasts are kept clean, the child probably will not get the infectious disease that may be prevailing in the neighborhood, showing that the entrance of these micro-organisms is largely through the alimentary canal.

The reason I asked Dr. Christopher the question I did is that a temperature above 212 degrees appears to me to devitalize and take out of the protoplasm in the milk what we want, and we can certainly render it sterile at a much lower temperature. Even in the face of fat and adipose tissue, the child may develop scorbutus for the want of an element that is lacking. When the baby is nursing from the mother's milk, it is drawing other things than milk, and other than microbes; but as life gives life, and iron sharpeneth iron, so the mother's milk, being a living substance. tends to prevent scorbutus, and the lack of it predisposes to scorbutus.

Dr. T. M. Rotch of Boston-All I can say in answer to the gentleman is that we have some who will digest 3 , but will take 1 and 2 badly. Let the fat be anywhere up to 4 and the sugar up to 7 , and you can make hundreds of thousands of combinations with these figures. But it is only once in many cases that you will need to change to get the proper combination for an individual case. In the vast majority of cases you will find everything will go well. It is in the difficult cases that $I$ find the greatest success in making these different combinations. I used condensed milk for years and made as good food as I could. All these things I have been over and so I can speak with reference to them. Some one has asked if there is not a difference in the analyses of mother's milk. In reply I would say that there is a trivial difference.

Dr. A. C. Cotron of Chicago. - In regard to the indication clinically for the increase or diminution of the various ingredients, I tried to slip that over to Dr. Rotch, but he dodged me. Now what am I to do? He said, never mind the egg but go on and trust to God and Rotch and you will get along all right. I acknowledge him as the father of this business, you will understand; but I am somewhat like the man whose lawyers told him to go ahead. "But," he said, "they will put me in jail." The lawyers told him they couldn't put him in jail. "But," he said, "I am in jail." Now we have gone ahead, by his advice, as long as we could, but we have had to do something else. The dairymen tell us to go ahead and they will feed their cows so well that their milk will melt in the babies' mouth, but it don' $t$ melt. Dr. Rotch remiuds us of the artist when he was asked what he mixed his colors with. He said he mixed them with brains. Dr. Rotch has not answered your question and I will not try to answer it. The babies have indigestible casein when I give them cow's milk, no difference what the laboratory men may say about giving milk that will melt in the mouth. When I add egg albumin they do very well. Then, under these circumstances, what shall I do? Hold to Rotch and lose my patient? In reply to the question as to how much and when, let me illustrate. I used to be a good sailor. Somebody asks, how hard to lean against the tiller and how hard to pull the sheet, and how hard to put the helm up? Why, how many things does that depend upon? You can not get the analysis of the mother's milk from the chemist and go and have something made exactly like it. You must feel your way along, just as the laparotomist must do when he examines the adhesions. But there are certain physiologic conditions that are well known. You know when a baby is rickety and scorbutic, and when he has tympany and indigestion he is not doing well, and you must feel your way along to get results. 